\title{
ISLET-CELL TUMOUR OF THE PANCREAS, WITH HYPOGLYCAEMIA
}

\author{
Robert S. MoNRo, F.R.C.S. \\ Consultant Surgeon, Ipswich and East Suffolk Hospital, Ipszich
}

Insulin-secreting tumours of the pancreas may present considerable problems in diagnosis and not a little difficulty in treatment. If the possibility of hypoglycaemia being the cause of attacks of altered consciousness associated with autonomic disturbance is thought of, it is not difficult to demonstrate its existence, but it is more difficult to demonstrate with certainty that such hypoglycaemia is due to an islet-cell tumour, and the difficulty and anxiety of the problem is further increased if laparotomy has already been undertaken with negative results.

Even when the diagnosis of organic hyperinsulinism is established, difficulties are not at an end, for the hyperinsulinism may on the one hand be due to an obvious and readily accessible adenoma, or on the other hand it may be due to a minute adenoma obscurely placed deep in the pancreas, or to multiple adenomata, or to ectopic adenomata, or to a carcinoma of the pancreas, or finally to diffuse hyperplasia of islet-cell tissue, so that the extent of surgery required may range anywhere from simple enucleation of an adenoma to possible total pancreatectomy. Furthermore, overshadowing any question of operation is always the problem of the patient's everincreasing obesity.

A case is here described illustrating some of the difficulties to be encountered in diagnosing and treating islet-cell tumours of the pancreas and suggesting that when a first exploration of the pancreas has been fruitless, a second exploration after a lapse of some months may not prove as difficult or as unrewarding as anticipated, possibly as a result of progressive enlargement of the adenoma responsible.

\section{Case Report}

F.H., a widow, aged 57, attended the Ipswich and East Suffolk Hospital in January 1955 complaining of attacks of giddiness for two years. These attacks had been more severe in the last year causing her to faint and lose consciousness repeatedly. The onset of the attacks was heralded by a seeming loss of touch with her surroundings; they varied in severity and frequency sometimes occurring daily, at others ten days or more passing without an attack; they presented varying degrees of dizziness and unconsciousness with muscular incoordination, causing her to stagger and fall about, sometimes causing diplopia, and sometimes causing difficulty in speech which degenerated into uncouth noises. The patient had been variously considered as epileptic or drunk and on one occasion when she developed an attack in the presence of a visiting insurance agent, he had thought it necessary to telephone the police The attacks usually lasted one to two hours, but on one occasion had lasted as long as six hours They were not predictable in their onset and dip not seem particularly related to her meals, but attacks had never occurred within less than one hour after a meal and she had noticed that latterly there had been a definite tendency to be queer first thing in the morning unless she had a sweet drink in the middle of the night, so much so that she had developed the habit of setting her alarm clock to call her at 2 a.m. for that purpose. She had also noticed that attacks could be terminated abruptly by taking a sweet drink.

The only other notable symptom was that she had been gaining weight. Some years previously her normal weight had been in the neighbourhood of 9 st. $2 \mathrm{lb}$. When she first attended hospital in I 955 her weight was I I st. I I lb. Her appetite was normal, there had been no disturbance of the function of her bowels or of micturition, she did not drink excessively, though she was in the habit of taking a daily glass of ale, she smoked approximately ro cigarettes a day.

The patient was one of 12 children, her father had died of pneumonia and her mother from a carcinoma of the bowel. Four of her siblings had died of unrelated complaints, her husband had died following an operation for duodenal ulcer. She had a son and a daughter, both of whom were well. 
There was nothing relevant in the patient's past history. She had had an appendicectomy in I924 and pneumonia in 1940; her menopause had occurred in 1944 at the age of 46 .

Physical examination showed a stout, rather red-faced woman, but there was no hirsutes or coarsening of the features, no unusual pigmentation and no spider naevi. Respiratory and cardiovascular systems were normal, her pulse rate 74 per minute, her blood pressure $150 / 85$. Her abdomen was fat and exhibited an appendicectomy scar but there was no other detectable abnormality. Her limbs were normal, there was no detectable abnormality of the central nervous system, and her intellect and mentality, apart from the times of the attacks, appeared perfectly normal. There was no urinary abnormality.

The possibility of the attacks being epileptic was considered, and in this connection X-rays of the skull proved normal, analysis of the cerebrospinal fluid was normal, W.R. was negative and electro-encephalogram was normal. The possibility of myxoedema was entertained, but B.M.R. was plus 8 , iodine uptake and excretion indicated normal thyroid function, and serum cholesterol was $150 \mathrm{mg} . \%$; I7-ketosteroid excretion was $5.8 \mathrm{mg} . / 24$ hours. Estimation of the blood sugar showed definite hypoglycaemia at times, the lowest observed blood sugar being $19 \mathrm{mg}$. $/ 100 \mathrm{ml}$., but the standard glucose tolerance test was not strikingly abnormal and sometimes attacks appeared to occur without any extreme depression in blood sugar level. It was, however, repeatedly observed that attacks could be relieved or aborted by the administration of glucose.

It was concluded that the attacks of unconsciousness, associated as they were with variable but definite hypoglycaemia, in turn suggestively though somewhat variably related to starvation and relieved by the administration of glucose, were indicative of organic hyper-insulinism, and in May 1956 laparotomy was undertaken to explore the pancreas with a view to removing an islet-cell tumour.

At operation the abdomen was opened through an upper transverse incision, the whole neighbourhood of the pancreas was thoroughly explored though exposure was difficult owing to obesity. The spleen was mobilized with some difficulty, and haemorrhage from adhesions between it and the diaphragm necessitated its removal. The tail and body of the pancreas were fully mobilized without finding any adenoma, the second part of the duodenum was mobilized and the head of the pancreas turned forwards, again without finding any adenoma, and no adenoma could be found in any part of the walls of the lesser sac. The tail and body of the pancreas were therefore resected.
Subsequent microscopic examination of the pancreatic tissue removed showed islets of normal size and structure, but gave the impression of there being a distinct increase in their number. Post-operatively the patient's recovery was relatively uncomplicated and for a few weeks there appeared to be a remission in the attacks, but before very long they had returned with even greater severity and frequency. Moreover, the patient continued to gain weight, increasing to I3 st. $6 \mathrm{lb}$.

The problem posed by this relapse was the difficult one usual to cases where exploration for an islet-cell tumour has proved negative; one in which the prospect of success in any second laparotomy is overshadowed by the increasing difficulties engendered by the patient's everincreasing obesity. The question arose firstly as to whether the diagnosis might be at fault and the patient's hypoglycaemia due to some cause other than a super-abundance of islet-cell tissue. In the second place the possibility of the condition being due to a diffuse hyperplasia of islet tissue had to be considered, a consideration to which microscopy of the body and tail of pancreas removed gave some support. If this were so the possibility of a really radical sub-total pancreatectomy had to be considered. Finally there was the possibility that there was an islet-cell adenoma in the head of the pancreas which had eluded discovery. The prospect of finding it at a second exploration after covering the ground so thoroughly at the first seemed rather slight, particularly in view of the patient's ever-increasing weight, in which case the possibility of total pancreatectomy had to be considered with all that it entailed in terms of primary mortality and subsequent inconvenience and morbidity.

Checking over the matter of diagnosis again, it was re-established the attacks occurred when the patient had been fasting for several hours, particularly first thing in the morning, that they were associated with a variably low blood sugar, commonly below $30 \mathrm{mg}$. $/ 100 \mathrm{ml}$. and that they were promptly relieved by the administration of glucose. On the occasion of a glucose tolerance test, a low normal fasting blood sugar of $68 \mathrm{mg}$. $/ 100 \mathrm{ml}$. was found with a considerable rise to $190 \mathrm{mg}$. $/ 100$ $\mathrm{ml}$. at two hours, returning to a low normal level of $50 \mathrm{mg}$. $/ 100 \mathrm{ml}$. at six hours, and persisting at this level until the test was discontinued at the eighth hour. Throughout the time of this particular test there was no loss of consciousness. This reaction to glucose seemed clearly to rule out any question of functional or alimentary hypoglycaemia, but the comparatively large initial rise and slow subsequent fall suggested possible hepatogenous hypoglycaemia. All liver function tests were 
normal, however, and the facts still seemed most compatible with organic hyper-insulinism.

In the course of investigation, however, it had been thought desirable to endeavour to control the attacks by dietary measures, instituting a high protein diet and at the same time restricting carbohydrate intake in an effort to combat the tendency to increasing obesity. It had been noticed that attacks seemed more frequent while the patient was taking a high protein diet, and the possibility of protein sensitivity, and notably amino-acid leucine sensitivity, was considered. It was demonstrated that a test dose of $25 \mathrm{~g}$. of Casilan produced an appreciable fall in fasting blood sugar level, but on the other hand a similar test dose of leucine produced no significant change.

It was decided to transfer the patient to the Middlesex Hospital to sort out these various biochemical complexities. At the Middlesex Hospital the patient was in the care of Dr. Nabarro and Mr. LeQuesne. The aggravation of the patient's hypoglycaemia by administration of protein could not be confirmed; indeed, it was conclusively demonstrated over a series of days that on a low protein diet ( $40 \mathrm{~g}$./day) of constant carbohydrate and calorie value the attacks were more frequent. The effect of a 12-hour fast was also reinvestigated and the patient lapsed into unconsciousness at 12 hours. Serial blood sugars (Folin and $\mathrm{Wu}$ ) and blood glucose estimations (glucose oxidase method) ran as indicated below:

\begin{tabular}{|c|c|c|c|c|c|c|c|}
\hline & $\begin{array}{c}\text { I } \\
\text { hr. }\end{array}$ & $\begin{array}{c}3 \\
\text { hrs. }\end{array}$ & $\begin{array}{c}5 \\
\text { hrs. }\end{array}$ & $\begin{array}{c}7 \\
\text { hrs. }\end{array}$ & $\begin{array}{c}9 \\
\text { hrs. }\end{array}$ & $\begin{array}{l}12 . \\
\text { hrs }\end{array}$ \\
\hline & & \multicolumn{6}{|c|}{ mg./roo ml. } \\
\hline $\begin{array}{l}\text { Folin and Wu } \\
\text { Glucose oxidase }\end{array}$ & $\begin{array}{l}\cdots \\
\cdots\end{array}$ & $\begin{array}{l}76 \\
42\end{array}$ & $\begin{array}{l}55 \\
24\end{array}$ & $\begin{array}{l}53 \\
24\end{array}$ & $\begin{array}{l}75 \\
45\end{array}$ & $\begin{array}{l}90 \\
45\end{array}$ & $\begin{array}{l}61 \\
28\end{array}$ \\
\hline
\end{tabular}

Blood taken at the end of this series of investigations while the patient was still unconscious showed an insulin activity by the Vallance-Owen rat-diaphragm method of 350 micro-units/100 ml., a significantly raised figure. In the absence of any demonstrable broad spectrum protein sensitivity it was considered unnecessary to investigate amino acid sensitivity in detail, and it was concluded that the hypoglycaemic attacks and hyperinsulinism were attributable either to an islet-cell adenoma which had hitherto escaped detection, or to diffuse hyperplasia and it was further concluded that the appropriate line of action was to re-explore the pancreas.

This second operation was carried out by Mr. LeQuesne and Mr. Monro on October I, $195^{8}$, two years and five months after the original exploration at Ipswich. The head of the pancreas showed no abnormality anteriorly, but on mobiliz- ing the second part of the duodenum and turning this and the head of the pancreas forward as had $\frac{2}{3}$ been done at the first operation, an obvious adenoma $\mathrm{r} .5 \mathrm{~cm}$. in diameter was seen and readily $\stackrel{\varrho}{c}$ enucleated. Post-operatively, the patient developed a well marked hyperglycaemia, the blood $\stackrel{5}{\rightarrow}$ sugar ranging as high as $314 \mathrm{mg} . \%$ and necessi- $\bar{O}$ tating as much as 100 units of soluble insulin in 흘 24 hours for its control. The diabetes, however, $\frac{\bar{c}}{\vec{b}}$ proved transient and it was possible to stop $\frac{\varnothing}{\circ}$ insulin administration three weeks after her operation. The patient has since remained well ${ }_{0}^{\text {s }}$ and has had no further attacks.

\section{Comment}

This lady's case illustrates many of the problems which beset the management of insulin 3 . secreting islet-cell tumours of the pancreas. Not $\dot{\omega}$ a few of these cases have in the past been rescued from psychiatric clinics or have been suspected of $\vec{\omega}$ cerebral tumours, ${ }^{7}$ but if the diagnosis is thought $\overrightarrow{ }$ of in connection with attacks of coma or altered 8 consciousness it can usually be brought to $a$ 음 certain and satisfactory conclusion. Meticulous differentiation of causes of hypoglycaemia other $z$ than islet-cell tumour must, however, be made, $\frac{0}{\circ}$ for major surgical issues may hang in the balance $\triangle$ and initial laparotomy may prove disappointinge $\vec{\oplus}$ negative.

The patient fulfilled the criteria of Whipple triad, 11 presenting attacks of unconsciousness, as sociated with blood sugar levels below $50 \mathrm{mg}$./100 $\mathrm{ml}$. and relieved by the administration of sugar. She also exhibited the criterion instanced by

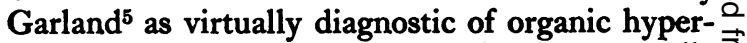
insulinism, namely, blood sugar levels repeatedly음 below $30 \mathrm{mg}$./ $100 \mathrm{ml}$., but she also exhibited a phenomenon not uncommonly causing difficulty in diagnosis in these cases, ${ }^{5}$ namely, that the onset of her attacks bore a very inconstant relationship to $\frac{\text { 을 }}{3}$ her blood sugar levels, so that although on a number of occasions no attacks developed when the 3 . blood sugar was below $30 \mathrm{mg} . / 100 \mathrm{ml}$., at other times attacks were observed to develop when the $\frac{\circ}{2}$ blood sugar was more than $50 \mathrm{mg}$. $/ 100 \mathrm{ml}$.

The patient's glucose tolerance test was fairly typical of her condition, exhibiting a slow and moderate rise and subsequent slow fall. It also illustrated the importance of prolonging the test $N$ for 12 hours or to the point of coma; for an eight- $N$ hour test in her case produced no conclusive N information, and it was only when the test had ${ }_{\sigma}^{\omega}$ been prolonged for 12 hours that coma developed even then it was interesting that the blood sugar? level (Folin and $\mathrm{Wu}$ ) at that time was not the lowest recorded during the test and was well above $50 \mathrm{mg} . / 100 \mathrm{ml}$. Morley? has emphasized the importance of activity and even of exertion during $\overparen{\mathbb{\Phi}}$ 
the performance of a glucose tolerance test if a significant result is to be obtained, while Garland, ${ }^{5}$ commenting on the discrepancy which may be present between the blood sugar levels and the onset of attacks, considers that it may be the rate of development of hypoglycaemia rather than the absolute levels of the blood sugar which may be significant. Hepatogenous hypoglycaemia gives a glucose tolerance test with progressively low figures as the test is prolonged, but in these cases there is a characteristically abnormal hyperglycaemia initially. Psychosomatic hypoglycaemia gives an oscillating curve in which an abnormally low swing is usually followed by a return to a normal fasting level within four hours. ${ }^{5}$

Certain adjuncts to diagnosis have been described, notably the demonstration of insulin hypersensitivity, and the direct estimation of plasma insulin levels. Insulin sensitivity is demonstrated by giving a test dose of as little as 5 units of soluble insulin, which in cases of isletcell tumour is likely to produce coma. ${ }^{5}$ Plasma insulin levels can be estimated by the rat-diaphragm method of Vallance-Owen;10 a raised plasma insulin level was found in this patient.

Dietary hypoglycaemias may have to be considered, particularly in children. It has been observed that protein feeding in diabetics may lower the blood sugar and may be a means of diminishing the requirements of insulin. ${ }^{9}$ In children a familial sensitivity to certain amino acids, notably leucine, presenting with hypoglycaemia and convulsions or coma, has been reported. ${ }^{3}$ The possibility of there being protein sensitivity was entertained in this case as it had at one time appeared that a high protein diet increased the incidence of her hypoglycaemic attacks, and on one occasion a test dose of a broad spectrum protein appeared to produce an appreciable fall in blood sugar. However, with subsequent repetition of these tests against a more constant dietary background protein sensitivity as a factor in her hypoglycaemia could not be confirmed. It is, moreover, a feature of leucine sensitive hypoglycaemia in children that they grow out of the condition, and hypoglycaemia from this cause is unlikely to be encountered in adults. The reverse, of course, can be said of children in relation to islet-cell tumours in that it is extremely unlikely that hypoglycaemia in an infant or young child is due to such a tumour. ${ }^{6}$ Even though remarkable degrees of hypoglycaemia well below $30 \mathrm{mg}$./100 ml. can occur in children, such levels are remarkably well tolerated and are only exceptionally due to organic hyperinsulinism.

There is this contrast in pathology between functional hyperinsulinism in children and organic hyperinsulinism in adults and the contrast is con- tinued in relation to treatment, for conservative methods are essentially applicable to children, ${ }^{6}$ whereas in adults with organic islet tissue changes operation is the only really satisfactory course. In the case of the patient under consideration, the possibility of treatment by conservative methods was explored, and was explored all the more keenly when her initial laparotomy had proved fruitless, but in the final event it was abandoned and her second operation proved successful. Dietary control may be reasonably effective in cases of only mild severity, ${ }^{5}$ but is open to the objection of producing extreme and everincreasing obesity.11 Alloxan has been used to produce experimental diabetes in dogs, but its use in humans for the treatment of hyperinsulinism has proved unsatisfactory and is fraught with the hazards of renal tubule degeneration and hepatic necrosis. ${ }^{2}$ Endocrine therapy has been employed with considerable success, in some cases of hyperinsulinism in children, ${ }^{6}$ and it is possible that some measure of control may be obtainable in cases of islet cell tumour. Certainly adrenocortical hormone has some anti-insulin activity, but its application to hyperinsulinism due to islet-cell tumour has proved disappointing, ${ }^{2}$ as has also the use of pituitary growth hormone as an anti-insulin agent. ${ }^{1}$ These various possibilities were considered in this lady's case and with particular care after her initial fruitless laparotomy, but the comparative unsatisfactoriness of the reported medical treatment of organic hyperinsulinism, combined with the comparative certainty of the existence of an abnormal mass of islet tissue remaining in her pancreas, led to the proper conclusion that the head of her pancreas had to be re-explored.

Various possibilities were envisaged before the patient's second operation. It seemed quite likely that a diffuse hyperplasia of islet-cell tissue was present which would require a sub-total resection of the pancreas comparable to thyroidectomy for thyrotoxicosis. Alternatively, it might be that such a sub-total resection might remove a microscopic adenoma which had eluded macroscopic detection. Should such a sub-total resection of the pancreas fail, the possibility of the need for a third operation and total pancreato-duodenectomy had to be envisaged. Only a very faint hope was entertained that an enucleable adenoma might be found since the first exploration had been so thorough, but in the event this proved to be the case.

This discovery of a relatively obvious adenoma at second operation is a by no means unique occurrence. Whipple ${ }^{11}$ reports 27 cases of isletcell tumours removed by operation, eight of which were found at the second laparotomy, and 
in seven of these the tumour was in the head of the pancreas. Cattell, ${ }^{2}$ in a series of 12 cases, describes one in which a tumour was found at second exploration in the uncinate process. Smith, ${ }^{8}$ in a series of three cases, describes one in which at first operation two tumours were removed from the pancreas; symptoms, however, recurred and an extensive resection was planned, but on mobilizing the tail of the pancreas a third adenoma was found and its removal led to cure without further resection. A further single case is described by Black et al.,1 where intensive medical measures were employed without success following an initial negative laparotomy, but at subsequent second operation an adenoma was found and removed without difficulty.

To explore the pancreas thoroughly is not an easy task, particularly in subjects in whom obesity is part of their condition, but this rather frequently recurring history of removal of an adenoma with relative ease from areas already explored at first laparotomy might indicate that the tumours have grown and become more obvious in the interim. There would seem perhaps to be something to be said in these cases for not re-exploring the pancreas too precipitately; the interim may profitably be spent in checking diagnostic details and possibly in the investigation of medical measures for control. This deliberate procrastination may facilitate the second operation and result in the easy removal of a simple adenoma, simply identified and simply removed, allowing avoidance of the more hazardous and potentially more morbid operation of sub-total resection of the head of the pancreas.

My thanks are due to Mr. D. H. Patey and
Dr. J. D. N. Nabarro for allowing me to refer to the case records at the Middlesex Hospital, and to Mr. L. P. LeQuesne for inviting me to take part in the second successful operation.

\section{Summary}

A case of insulin-secreting islet-cell tumour of the pancreas is described in whom the first laparotomy proved negative and a partial pancreatectomy was performed. At second operation more than two years later an adenoma was easily identified and removed from the head of the pancreas. Methods of diagnosis are evaluated and methods of medical management are discussed.

Operation is the only satisfactorily effective treatment in adults. The surgeon should not be too discouraged by a fruitless search at the first laparotomy. Partial pancreatectomy then will narrow the field for any subsequent exploration and at second operation there is a reasonable chance that an adenoma will be found and removed without undue difficulty.

\section{REFERENCES}

I. BLACK, K. O., MACDOUGLAS, I., REID, E., and YOUNG, F. G. (1952), Lancet, i, 19.

2. CATTELL, R. B., and WARREN, K. W. (1953), 'Surgery of the Pancreas.' Philadelphia and London: W. B. Saundegs

COCHRANE, W. A, PAYNE, W. W. SIMPKISS, M.

and WOOLF, L. I.' (1956), $\mathscr{f}$. clin. Invest., 35, 41 I.

4. COHEN, H. (1950), Ann. roy. Coll. Surg. Engl., 6, 3.

5. GARLAND, H. (1958), Brain, 81, 485.

6. MCQUARRIE, I. (1954), Amer. F. Dis. Child., 87, 399.

7. MORLEY, J. (1952), Brit. F. Surg., 40, 97.

8. SMITH, M. (1959), Ibid., 47, 155.

9. SRINIVASAN, M. (1957), Lancet, ii, 317.

Io. VALLANCE-OWEN, J., and HURLOCK, B. (1954), Ibid., i, 68 .

I1. WHIPPLE, A. O. (1944), Surgery, 16, 289.

\section{RUTHIN CASTLE, NORTH WALES}

A Clinic for the diagnosis and treatment of Internal Diseases (except Mental or Infectious Diseases). The Clinic is provided with a staff of doctors, nurses, technicians, modern Radiological and Physiotherapy departments.

The surroundings are beautiful. The climate is mild. There is central heating throughout. The annual rainfall is $\mathbf{3 0 . 5}$ inches, that is less than the average for England.

The Fees are inclusive and vary according to the room occu jied.

For particulars apply to THE SECRETARY, Ruthin Castle, North Wales. 